\title{
An Unusual Mandibular Second Molar Mimicking Maxillary First Molar - A Rare Occurrence
}

\section{Srinivasulu Sakamuri and Sreekanth Kumar Mallineni*}

Narayana Dental College, Nellore, Andhra Pradesh, India

*Corresponding author: Sreekanth Kumar Mallineni, Narayana Dental College, Nellore, Andhra Pradesh, India, Tel: +918985833533; E-mail: drmallineni@gmail.com

Received date: December 02, 2017; Accepted date: December 20, 2017; Published date: January 03, 2018

Copyright: (C) 2018 Sakamuri S. This is an open-access article distributed under the terms of the creative Commons Attribution License, which permits unrestricted use, distribution and reproduction in any medium, provided the original author and source are credited.

Citation: Sakamuri S. An Unusual Mandibular Second Molar Mimicking Maxillary First Molar - A Rare occurrence. Periodon Prosthodon. 2018, Vol.4 No.1:01

\section{Abstract}

Dental anomalies are common in the permanent dentition when compared to the primary dentition, and more common in the maxillary arch. These could be localized to one or two teeth and could be generalized, affected by all teeth most of the times, which might be apart from syndromic or systemic disorders. The purpose of this report is to describe a unique case mandibular second permanent molar exhibiting oblique ridge and a buccal accessory cusp resembling the maxillary molar in a 13year-old female.

Keywords: First molar; Permanent dentition; Mandibular arch; Maxillary arch; Dental anomaly

\section{Introduction}

The dimension and morphology of teeth are noticeable aspects of any given phenotypic disparities. [1]. The commonly seen developmental dental anomalies of the teeth include size, shape, and number and structure [2]. These dental anomalies have always been of a great interest to the clinician from the clinical and the research point of views. Dental anomalies are commonly seen in the permanent dentition than the deciduous dentition, whilst, very frequent in the maxillary arch than in the mandibular arch [3]. These anomalies may be localized to one or two teeth or could be generalized, affected by all teeth most of the times [4,5]. It is frequently difficult to differentiate whether the abnormality of a tooth is a true anomaly or an extreme variation in morphology of a tooth. These unusual formations of the teeth are very rarely noticed on regular examination [6]. Concrescence, cusp of carabelli, dens evaginatus, dilaceration, double tooth, prostyloid and talon cusp are frequently seen abnormalities of the teeth $[2,7]$. The majority of these variations in shape affect the crown of the tooth [8]. The patterns of grooves and fissures on the occlusal surface of the maxillary molars show substantial variation with mandibular molars. It has been reported that buccal accessory cusps are very rare in mandibular molars [2,9] and presence of an oblique ridge even rare in mandibular molars. As the variations in crown has not been reported in the literature, and the purpose of the present case report was to describe an unusual mandibular second molar with an oblique ridge and buccal cusp resembling the crown of the maxillary molar with cusp of Caraballi.

\section{Case Report}

A 13 year and 2 months old girl attended for a regular dental check-up. Her medical and dental histories were unremarkable, and she was the first child of a healthy nonconsanguineous family. The intra-oral examination revealed that she was in the permanent dentition with adequate oral hygiene. All the teeth were erupted according to her age, tooth 37 showed atypical morphology of maxillary molar appearance, a unique feature of having four cusps with an oblique ridge running from the mesio buccal to the distolingual cusp, with an accessory cusp resembling the maxillary molar (Figure 1). A noticeable bridge of enamel connected this to the distobuccal surface of the tooth. The cusp neither interfered with the occlusion nor irritated the buccal mucosa during mastication and speech. The occlusal surface of tooth 37 resembled as maxillary first molar with a cusp of Caraballi) (Figure 2). Fissure sealant was placed on the occlusal surface of the tooth and the child has been kept under regular review. 


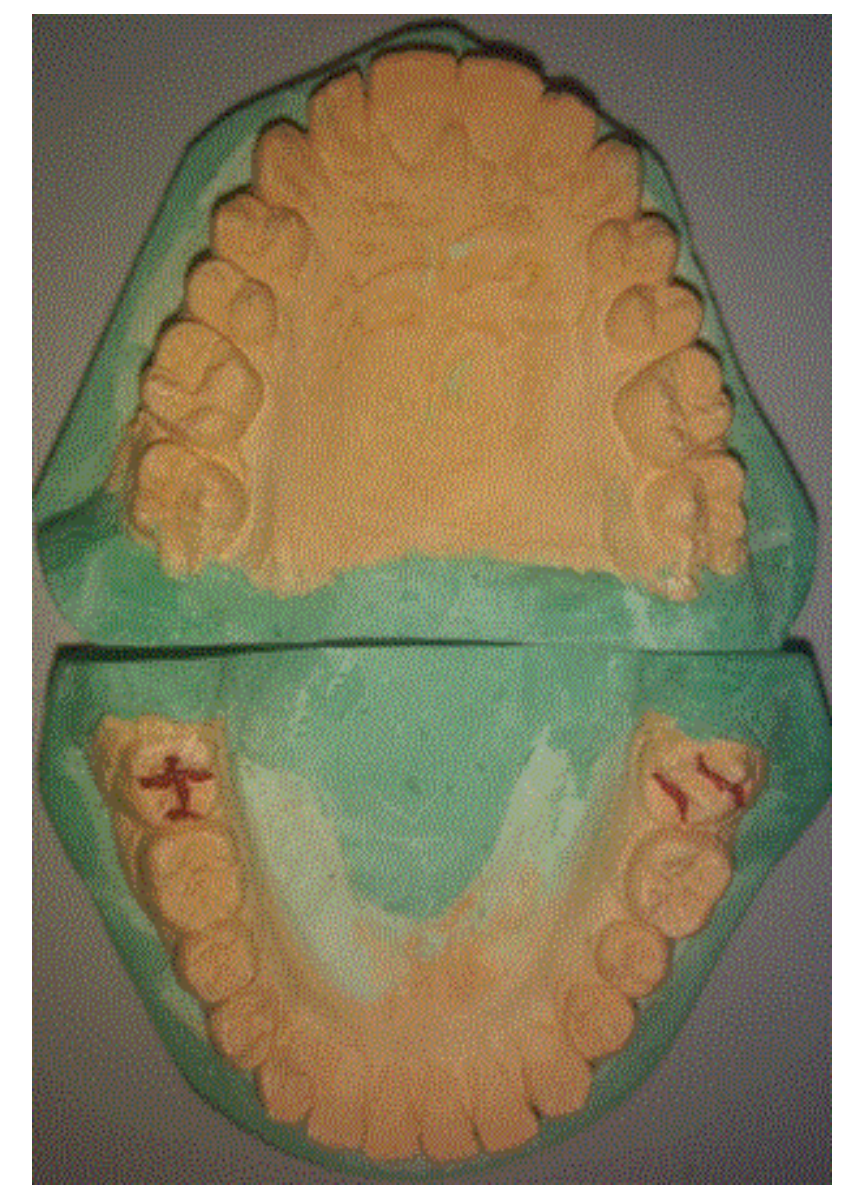

Figure 1 Dental study cast showing occlusal view of maxillary and mandibular arches.

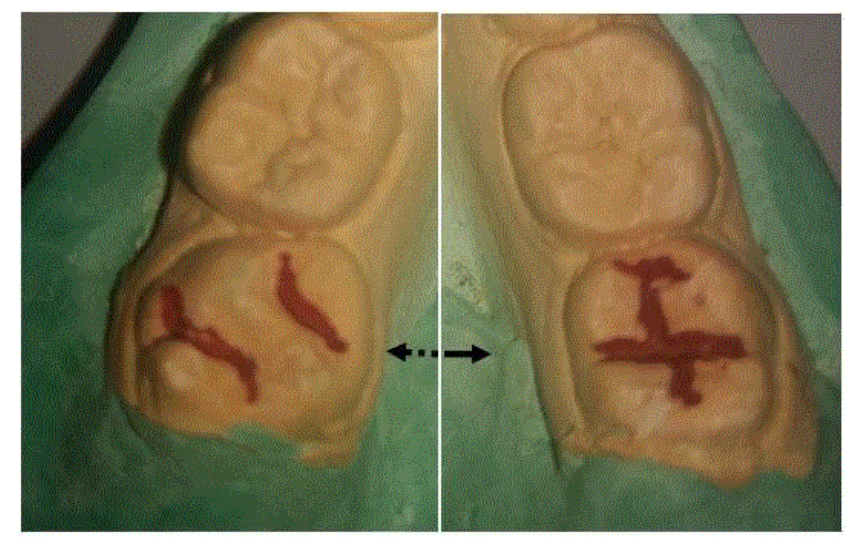

Figure 2 Mandibular second molars tooth 37 (doted arrow) showing maxillary molar morphology and tooth 47 showing (arrow) exhibiting usual morphology.

\section{Discussion}

Morphological and developmental anomalies of teeth are not regularly observed in the clinical scenario. Nonetheless, these abnormalities are relatively less noticeable when compared to the common dental problems such as dental carious lesions, gingivitis and periodontal diseases [10]. Shovel shaped incisors, molar cusp pattern and number and especially cusp of Caraballi are common morphological variants in different races and ethnicities [11]. Permanent first molars are called as key teeth for occlusion and comparatively the mandibular first molar may show numerous anatomical abnormalities than the maxillary molars [7]. The abnormalities in the morphology of root containing third root and different cuspal pattern of the crown anatomy had have been reported. Disparities in the permanent mandibular molar crowns are sometimes reported with, as an extra cusp on the mesiobuccal surface [11] (prostostylid) and as a sixth cusp (tuberculum sextum or tuberculum intermedium) [7].

Maxillary permanent molar shows various characteristics morphological features compared to mandibular permanent molars that include the presence of an oblique ridge and the presence of a carabelli trait on the palatal surface. These two features are considered as unique features of maxillary molars. In the present case the tooth 37 resembles as mirror image of tooth 16. The possible explanation of this was the oblique ridge on the occlusal surface of tooth 37 involved from mesiobuccal cusp to distolingual cusp, and accessory cusp has been observed on the buccal surface as in the aspect that the crown, resembling the maxillary molar with the Carabelli cusp. So far, only two cases reported in the literature on similar observations. A 23-year male, exhibited mandibular premolars and the molars of the left arch were remarkably similar to the maxillary posteriors, while the mandibular first molar on the right side was a mixture of both the maxillary and the mandibular molars [7]. However, in the present case only tooth 37 exhibited appearance of maxillary molar morphology. Most recently, Madhushankari et al. reported in a 20-year-old patient with left mandibular first molar exhibiting four cusps with an oblique ridge [12]. Nonetheless, the present case reported similar findings with extra cusp on the buccal surface which not reported earlier. The aetiology for this kind of presentation is questionable and not been documented clearly [13]. The treatment options were discussed that placement of fissure sealant, lateral grinding and, occlusal grinding. Since, there is neither occlusal interference nor trauma to buccal mucosa none of the treatment options were done. Fissure sealant was placed as preventive purpose. The accessory cusps on the palatal side of the maxillary molars called as cusp of Carabelli [14,15] while, buccal surface on the mandibular molars called as protostylid. In distinct to these reports, an accessory cusp was noted on the buccal surface of the mandibular molar with maxillary appearance, and our comprehensive literature search didn't find similar finding. In the clinical point of view these accessory cusps are very important to deal with, and mostly if there is any pulp involved or if the tooth needed crown preparation.

\section{Conclusion}

Morphological and developmental abnormalities of teeth are very rare reported. Nevertheless, a careful examination of the hard tissue in oral cavity may help the clinicians for the 
better treatment planning. Mandibular Second molar mimicking maxillary first molar is extremely rare scenario and these type variations are rarely reported. This type of new findings may be helpful for the dental anthropologist and forensic odonatologist.

\section{References}

1. Mallineni SK, Manan NM, Lee CK, King NM (2013) Talon cusp effecting primary dentition in two siblings: a Case Report. Rom J Morphol Embryol 54: 211-213.

2. King NM, Tongkoom S, Itthagarun A, Wong HM, Lee CK (2008) A catalogue of anomalies and traits of the primary dentition of southern chinese. J Clin Pediatr Dent 32: 139-146.

3. Brook AH (1974) Dental anomalies of number, form, and size: their prevalence in British school children. J Int Assoc Dent Child 5: 37-53.

4. Brook AH (1984) A unifying aetiological explanation for anomalies of human tooth number and size. Arch Oral Biol 29: 373-378.

5. Mallineni SK, Jayaraman J, Yiu CK, King NM (2012) Concomitant occurrence of hypohyperdontia in a patient with marfan syndrome: a review of the literature and report of a case. J Investig Clin Dent 3: 253-257.

6. Woelfel JB, Scheid RC (1997) Dental Anatomy: Its Relevance to Dentistry. 5th edn, Williams and Wilkins, USA.
7. Guttal KS, Naikmasur VG, Bhargava P, Bathi RJ (2010) Frequency of developmental dental anomalies in the Indian population. Eur J Dent 4: 263-269.

8. Curzon ME, Curzon JA, Poyton HG (1970) Evaginated odontomes in the Keewatin Eskimo. Br Dent J 129: 324-328.

9. Ling JKY, Wong RKW (2010) Incisal Morphology of Southern Chinese. The Open Anthrop J 1: 19-25.

10. Ghaznawi HI, Daas H, Salako NO (1999) A clinical and radiographic survey of selected dental anomalies and conditions in Saudi Arabiain population. The Saudi Dent J 11: 8-13.

11. Scott GR, Turner CG (1997) The Anthropology of Modern Human Teeth: Dental morphology and its variation. Cambridge University Press.

12. Madhushankari GS, Basavanna RS, Deepshikha D, Sonika M (2012) Emphasizing a new developmental variation of the mandibular molars - A Mermaid in Dentistry? J Clin Diag Res 5: 402-403.

13. Skinner MM, Wood BA, Hublin JJ (2009) Protostylid expression at the enamel-dentine junction and enamel surface of mandibular molars of Paranthropus robustus and Australopithecus africanus. J Hum Evol 56: 76-85.

14. Cobourne MT (1999) The genetic control of early odontogenesis. $\mathrm{Br} J$ Orthod 26: 21-28.

15. Kondo S, Townsend GC (2006) Associations between Carabelli trait and cusp areas in human permanent maxillary first molars. Am J Phys Anthropol 129: 196-203. 